University of Nebraska - Lincoln

DigitalCommons@University of Nebraska - Lincoln

Management Department Faculty Publications

Management Department

2011

\title{
Leader development and the dark side of personality
}

Peter D. Harms

University of Nebraska - Lincoln, pharms@gmail.com

Seth M. Spain

University of Nebraska-Lincoln

Sean T. Hannah

United States Military Academy

Follow this and additional works at: https://digitalcommons.unl.edu/managementfacpub

Part of the Management Sciences and Quantitative Methods Commons

Harms, Peter D.; Spain, Seth M.; and Hannah, Sean T., "Leader development and the dark side of personality" (2011). Management Department Faculty Publications. 82.

https://digitalcommons.unl.edu/managementfacpub/82

This Article is brought to you for free and open access by the Management Department at DigitalCommons@University of Nebraska - Lincoln. It has been accepted for inclusion in Management Department Faculty Publications by an authorized administrator of DigitalCommons@University of Nebraska - Lincoln. 


\title{
Leader development and the dark side of personality
}

\author{
P.D. Harms ${ }^{\mathrm{a}, *}$, Seth M. Spain ${ }^{\mathrm{a}}$, Sean T. Hannah ${ }^{\mathrm{b}}$ \\ a University of Nebraska, Lincoln, USA \\ b Center for the Army Profession and Ethic, West Point-United States Military Academy, USA
}

\section{A R T I C L E I N F O}

Available online 14 May 2011

\section{Keywords:}

Leadership

Development

Personality

Subclinical

\begin{abstract}
A B S T R A C T
The present study investigates the role of subclinical personality traits as determinants of leader development over time. In previous literature, subclinical traits have been identified as potential causes of leader derailment. However, leader development researchers have argued that developmental interventions based on increasing self-awareness may be effective at mitigating the negative effects of these character flaws. Using a multi-wave, multi-method longitudinal study of military school cadets we evaluate the impact of subclinical traits on externally-rated measures of leader development over a three year period. Results demonstrated that adding subclinical traits to models of development significantly increased model fit and that the relationship between "dark side" personality traits and performance and training is more complicated than originally thought. Moreover, subclinical traits were associated with different developmental trajectories over time. Implications for leadership development research and practice are discussed.
\end{abstract}

(c) 2011 Elsevier Inc. All rights reserved.

While there has been a recent movement toward assessing positive aspects of character in the leader development literature (e.g. Linley, Woolston, \& Biswas-Diener, 2009; Rath \& Conchie, 2009), scholars have also begun to recognize the importance of character flaws as determinants of both leader performance and responsiveness to developmental interventions (Hogan, Hogan, \& Kaiser, 2010). Despite this, there has been almost no empirical research utilizing large samples of individuals undergoing leadership training over time to assess the influence of personality traits in general, and character flaws in particular, on leader development. Consequently, little is actually known about how effective developmental feedback about potential character flaws is in such settings. The present study aims to address the lack of research in this area by evaluating the importance and complex role of "dark side" traits in the leader development process. To do so, we will make use of archival data from a cohort of military cadets undergoing training in leadership over three years. Using a multi-method framework, we will show the importance of taking such "dark side" personality characteristics into account when designing or evaluating the effectiveness of long-term leader development programs.

\section{Personality and leadership}

Although the association between personality and leadership outcomes is widely acknowledged (Hogan \& Kaiser, 2005), the vast majority of research in this area has attempted to link leadership outcomes with the phenotypic traits of the well-known Five Factor Model (FFM) or Big Five (Goldberg, 1993; McCrae \& Costa, 1995). For example, a meta-analysis on the relationship between the Big Five personality traits and leader effectiveness and emergence found that, with the exception of Agreeableness, each of the Big Five traits were robustly associated with leadership outcomes (Judge, Bono, Ilies, \& Gerhardt, 2002). A more recent metaanalysis on more specific individual differences (e.g. need for power, self-confidence, self-monitoring, and energy) that were

\footnotetext{
* Corresponding author.

E-mail address: pharms@unlnotes.unl.edu (P.D. Harms).
} 
theoretically linked with leader effectiveness found broad support for the role of personality traits in leader effectiveness outcomes (Hoffman et al., 2011).

Despite the overwhelming emphasis placed on the FFM by applied researchers, theoretical advances in the field of personality psychology have long since begun looking elsewhere for important individual differences. Current models of personality such as the Neo-Socioanalytic model (Roberts, Harms, Smith, Wood, \& Webb, 2006) make it clear that traits do not subsume other domains of personality (e.g. goals, interests, and motives) and that each of these distinct domains has unique relationships with important life outcomes. This paradigm shift is beginning to be seen in the leadership literature as well. Recent literature reviews of the personality-leadership relationship have emphasized the need to understand the motives and values of leaders (Hogan \& Kaiser, 2005) as well as other traits such as narcissism that are "beyond" the Big Five (Judge, Piccolo, \& Kosalka, 2009).

\subsection{Dark side personality traits}

One area of increasing interest in the search for important traits that are not captured by the Big Five is that of subclinical personality traits. Popularized by Paulhus (Paulhus \& Williams, 2002), subclinical traits represent a middle ground between "normal" personality traits such as the Big Five and "clinical" traits used to diagnose psychological pathologies. One might consider them personality quirks that do not greatly inhibit day-to-day functioning, but may cause severely negative outcomes in particular circumstances; such as during leadership social interactions. Paulhus identified the "Dark Triad" of narcissism, psychopathy, and Machiavellianism as the most widely studied subclinical traits (Paulhus \& Williams, 2002), but more recent work has extended beyond those traits. Within the fields of organizational behavior and leadership, the "dark side" measure that has received the most attention is the Hogan Development Survey (HDS; Hogan \& Hogan, 1997). The HDS uses Axis 2 personality disorders from the Diagnostic and Statistical Manual-IV (DSM-IV; American Psychiatric Association, 1994) as a framework. The HDS assesses 11 subclinical traits (for a description see Table 1) each of which are theorized to have possible short-term advantages, but also longterm detrimental effects on performance and leadership (Hogan \& Hogan, 1997; Hogan, 2007; Hogan \& Kaiser, 2005).

It should be noted that the titles used for the 11 HDS dimensions are euphemistic appellations for the more negatively worded DSM-IV Axis 2 personality disorders noted in Table 1. Although high scorers on the HDS would not necessarily meet diagnostic criteria for the DSM-IV, they possess broadly similar attributes but to a lesser extent. We cannot cover each of the 11 Axis 2 dimensions fully here and thus refer readers to the DSM-IV for further details (American Psychiatric Association, 1994). As an example, individuals falling in the average range of Skeptical are quite capable of trusting others, but those who are high on the Skeptical dimension would be described as demonstrating behaviors similar to indicators of the DSM-IV dimension of Paranoid, such as having a chip on their shoulder, being cynical, distrustful, fault-finding, easily angered, and suspicious of others' actions and intentions.

Although there has been increasing interest in the "dark side" of personality, empirical literature on the topic is scarce. Consequently, the topic of subclinical traits has gone largely ignored in the personality field as a whole (e.g., John, Robins, \& Pervin, 2008). There have, however, been some recent attempts to link subclinical traits with leadership and performance outcomes. For example, Moscoso and Salgado (2004) found negative relationships between task and contextual performance and a broad array of subclinical traits. Similarly, counterproductive work behaviors have been shown to be linked with trait narcissism (Penney \& Spector, 2002).

In terms of leadership research, several reviews of managerial derailment have pointed to negative personality traits as important antecedents of leader failures (Hogan \& Hogan, 2001; Kippenberger, 1997; Leslie \& Van Velsor, 1996; Lombardo, Ruderman, \& McCauley, 1988; Padilla, Hogan, \& Kaiser, 2007). In addition to this, recent research has linked dark side traits with leader emergence and performance. In a recent study comparing managers and non-managers in Great Britain, it was found that non-managers scored significantly higher on the HDS dimensions of Colorful, Diligent, and Dutiful (Furnham, Crump, \& ChamorroPremuzic, 2007). Similarly, several studies have reported that individuals with narcissistic personality are often nominated as leaders by groups (e.g. Brunell et al., 2008; Paulhus, 1998) or may be perceived as more leaderlike in employment interviews (e.g. Schnure, 2010). However, narcissistic individuals are often rejected by their groups over the long-term because of their arrogance and high-handedness (Paulhus, 1998). Benson and Campbell (2007) found that leader performance was negatively associated with high scores on the HDS dimensions of Excitable, Skeptical, Cautious, Leisurely, Mischievous, and Imaginative. Similarly, in a study of upper-level managers, the HDS dimensions showed validity coefficients ranging from -.28 to .09 for leader effectiveness ratings made by knowledgeable coworkers (Torregiante, 2005). Overall, negative relationships were found for all dimensions except Dutiful and Diligent. Interestingly, one study (Lindberg, 2006) found little evidence of negative effects for subclinical traits and only found a small, positive relationship between leader effectiveness and the HDS Dutiful dimension.

In terms of leadership style, in a study of senior managers in New Zealand, Khoo and Burch (2008) found negative relationships between transformational leadership ratings and the HDS dimensions of Cautious and Reserved. They also found a positive relationship between HDS Colorful and transformational leadership. This finding presented the possibility that HDS dimensions may serve as positive factors under some circumstances or with specific outcomes. Similar effects were found in a study by Davies (2004) where transformational leadership was negatively related to Excitable, Skeptical, Cautious, Reserved, Leisurely, and Dutiful while positive relationships were found for Colorful and Imaginative. Transformational leadership is not the only domain where positive links between subclinical traits and leadership outcomes have been found, however. In a recent study of managers, divergent thinking was correlated with high levels of Bold, Mischievous, Colorful, and Imaginative as well as low levels of Diligent, Dutiful, Cautious, Reserved, and Leisurely (Furnham, Crump, Batey, \& Chamorro-Premuzic, 2009). However, when considered together, only the relationships with Bold and Dutiful remained significant predictors. 
Table 1

Subclinical dimensions of the Hogan Development Survey.

\begin{tabular}{|c|c|c|c|}
\hline Subclinical trait & DSM-IV construct & Description of high scorers & DSM-IV descriptions \\
\hline Excitable & Borderline & $\begin{array}{l}\text { Moody and inconsistent concerns; being } \\
\text { enthusiastic about persons, ideas, and } \\
\text { projects and then becoming disappointed } \\
\text { in them }\end{array}$ & Inappropriate anger; unstable and intense relationships \\
\hline Skeptical & Paranoid & $\begin{array}{l}\text { Cynical, distrustful, overly sensitive to criticism, } \\
\text { and skeptical of others' true intentions }\end{array}$ & $\begin{array}{l}\text { Distrustful and suspicious of others; motives of others } \\
\text { are interpreted negatively }\end{array}$ \\
\hline Cautious & Avoidant & $\begin{array}{l}\text { Resistant to change and reluctant to take } \\
\text { even reasonable chances for fear of being } \\
\text { evaluated negatively }\end{array}$ & $\begin{array}{l}\text { Social inhibition; feelings of inadequacy; hypersensitivity } \\
\text { to criticism }\end{array}$ \\
\hline Reserved & Schizoid & $\begin{array}{l}\text { Socially withdrawn and lacking interest } \\
\text { in or awareness of the feelings of others }\end{array}$ & $\begin{array}{l}\text { Emotional coldness and detachment from relationships; } \\
\text { indifferent to criticism }\end{array}$ \\
\hline Leisurely & Passive-aggressive & $\begin{array}{l}\text { Autonomous, indifferent to the requests } \\
\text { of others, and often irritable when } \\
\text { others persist }\end{array}$ & $\begin{array}{l}\text { Passive resistance to performance expectations; irritable } \\
\text { when asked to do unwanted tasks }\end{array}$ \\
\hline Bold & Narcissistic & $\begin{array}{l}\text { Unusually self-confident, unwilling to admit } \\
\text { mistakes or listen to advice, and unable } \\
\text { to learn from experience }\end{array}$ & $\begin{array}{l}\text { Grandiose sense of self-importance and entitlement; } \\
\text { arrogant behaviors and attitudes }\end{array}$ \\
\hline Mischievous & Antisocial & Enjoys taking risks and testing the limits & $\begin{array}{l}\text { Disregard for the truth; impulsive; failure to conform } \\
\text { to social norms }\end{array}$ \\
\hline Colorful & Histrionic & Expressive, dramatic, and desires to be noticed & Excessive emotionality and attention-seeking \\
\hline Imaginative & Schizotypal & Acts and thinks in creative and unusual ways & $\begin{array}{l}\text { Odd beliefs and thinking; behavior or speech that is } \\
\text { eccentric or peculiar }\end{array}$ \\
\hline Diligent & Obsessive-compulsive & $\begin{array}{l}\text { Careful, precise, and critical of the } \\
\text { performance of others }\end{array}$ & $\begin{array}{l}\text { Preoccupations with orderliness, rules, and control; } \\
\text { inflexible }\end{array}$ \\
\hline Dutiful & Dependent & $\begin{array}{l}\text { Eager to please, reliant on others for support, } \\
\text { and reluctant to take independent action }\end{array}$ & $\begin{array}{l}\text { Difficulty making everyday decisions without excessive } \\
\text { advice and reassurance; unwilling to express disagreement }\end{array}$ \\
\hline
\end{tabular}

Descriptions taken from HDS manual (Hogan \& Hogan 1997). The DSM-IV Construct is the clinical-level psychopathology associated with a given HDS dimension.

\section{Personality and leader development}

While a great deal is known about the impact of personality on leadership, there is very little literature on the topic of how personality may influence changes in leader development or effectiveness over time. It is now well established that performance changes over time and that short-term predictors of performance may not necessarily predict long-term outcomes. For example, a variety of studies have demonstrated that the relationship between personality and performance outcomes changes over time (Lievens, Ones, \& Dilchert, 2009) or as one moves up the organizational hierarchy (Kaiser \& Craig, 2004). However, these studies do not specifically address the issue as to whether or not personality predicts changes in performance or leader effectiveness over time. To better understand the process by which this may occur, it is important to understand the leader development process itself.

Yet, as noted in our literature review there is very little empirical research linking any aspect of personality with leader development over time. Beyond this, although there have been a number of theoretical articles on the effects of subclinical personality traits in the workplace, there is little research relating subclinical personality traits to leadership outcomes. Moreover, there is no empirical research that we are aware of exploring the relationship between such subclinical personality traits and leader development. Consequently, the present study represents the first, large-scale study of "dark side" personality and leader development as well as one of the first studies exploring personality as a potential moderator of leader development over time.

\subsection{Leader development}

Leader development involves changes in the perceptions, motivations, competencies, and patterns of behavior of individuals in leadership positions in order to help them function in their roles more effectively. This can be achieved via formal or informal methods and may involve a few minutes to several years of time to complete. Different methods of leader development include formal and informal mentoring programs, multisource feedback, guided reflection, developmental assignments and mastery experiences, and role models (McCauley, 2008). The sample of military cadets under study (see The Present Study, below) experienced a leader development process that exposed them to several such interventions. Meta-analytic reviews of the leader development literature have shown that while leader development programs vary widely in their effectiveness, they tend to show positive effects on average (Burke \& Day, 1986; Collins \& Holton, 2004; Kluger \& DeNisi, 1996). Consequently, we hypothesize that:

Hypothesis 1. Leader development measures will show positive changes over time.

\subsection{Personality as a development moderator}

Although it is widely accepted that individuals differ in their rates of development in response to leader development programs (Day, Harrison, \& Halpin, 2009; Hannah \& Avolio, 2010; Lindsay, Foster, Jackson, \& Hassan, 2009), some major reviews of the 
leader development literature have largely ignored personality as a potential moderator of changes over time (e.g. Avolio, 2005). Despite this, prior literature tells us that individual differences are an important, commonly-found moderator of the effectiveness of interventions (Harkness \& Lilienfield, 1997; McCormick \& Burch, 2008) and, more specifically, that certain personality characteristics can be associated with the rate of developmental changes over time (Roberts, Wood, \& Caspi, 2008). For example, uncooperative individuals have been shown to be less likely to change their behavior in response to the prevailing cultural norms of their teams (Chatman \& Barsade, 1995). Consequently, some researchers have proposed that individuals with personality disorders such as narcissism may be either unwilling or unable to respond to developmental demands and would therefore be less likely to change in response to feedback (Robins \& Paulhus, 2001).

Hogan and colleagues have argued that a variety of personality factors serve as important moderators in the leader development process (Hogan \& Warrenfeltz, 2003; Hogan et al., 2010): First, that individuals must be high on self-control in order to pay attention for prolonged periods and be good students in general. Second, that self-confidence has a non-linear relationship with leader development feedback such that individuals who are either too high or too low on self-confidence will be less inclined to benefit from the feedback process. In general, self-confidence is beneficial in that it allows individuals to bounce back from negative feedback or criticism and to be self-assured of their ability to overcome such obstacles. However, highly overconfident individuals are less likely to accept negative feedback and may be dismissive of it. Individuals with low self-confidence are overly defensive and may lack the psychological resources needed to respond and adapt to perceived setbacks. According to Hogan (Hogan \& Warrenfeltz, 2003), a third individual difference that impacts responses to performance feedback is the psychologicalmindedness of the individuals receiving the feedback. Psychological-mindedness is the degree to which these individuals consider or think about the motives and feelings of themselves and others. Perceptive individuals will modify their patterns of behavior in order to best suit those around them while inattentive individuals typically behave in a very transactional manner with little concern for the feelings of those around them. Hogan argues that individuals with high psychological-mindedness will be more responsive to feedback because they are intrinsically motivated to be both self-aware and aware of how others perceive them. Finally, it has been argued that rationality, or the capacity for scientific thinking, is needed in order to respond well to feedback. Individuals who are dismissive of feedback tools or external data and who prefer to use their own intuition will resist having their opinions changed by others.

One finds similar lines of thinking in the developmental readiness literature. Although researchers in this area seldom conceptualize their variables of interest as personality factors, they argue that individual differences in goal orientation, selfawareness, developmental efficacy or confidence, self-complexity, and meta-cognitive ability all have a role to play in determining which individuals will be most receptive to developmental interventions (Avolio \& Hannah, 2009; Hannah \& Avolio, 2010; Hannah \& Lester, 2009). In a similar vein, Popper and Mayseless (2007) have argued that the psychological factors most related to leader development are self-confidence, having a pro-social orientation, being optimistic, and being high on Openness to Experience and motivation to lead.

There is little empirical literature available on the subject of the role of personality in development. Prior reviews of the training literature have called for more research into dispositional factors in trainees that may impact the success of training programs (Tannenbaum \& Yukl, 1992). A subsequent meta-analysis by Colquit, LePine, and Noe (2000) demonstrated significant positive relationships between conscientiousness and locus of control and transfer of training. Likewise, in a meta-analysis of the role of personality in job performance, Barrick and Mount (1991) showed robust relationships between Extraversion, Conscientiousness, and Openness to Experience in predicting training proficiency. Similarly, in a longitudinal sample of sales representatives, Conscientiousness was associated with changes in performance over time (Thoresen, Bradley, Bliese, \& Thoresen, 2004).

Outside the world of work, research on patients with clinical disorders has demonstrated that individuals high on Neuroticism respond more poorly to treatment (Mulder, 2002). Further, longitudinal studies of students have shown that having an incremental (as opposed to entity) theory of change is associated with positive development over time (Robins, Noftle, Trzesniewski, \& Roberts, 2005).

Within the leadership domain, Conscientiousness, Openness, and Emotional Stability have been associated with responsiveness to executive coaching (Stewart, Palmer, Wilkin, \& Kerrin, 2008). Using a typological approach, Kail (2007) showed that individuals with different personality types responded differently to a leader development intervention based on multi-source feedback. Specifically, he showed that higher levels of Extraversion and lower levels of Openness, Neuroticism, Agreeableness, and Conscientiousness were associated with greater positive changes on leader relational performance (i.e. being approachable, supportive, and understanding). On the other hand, lower levels of Extraversion and Openness, but higher levels of Agreeableness and Conscientiousness were associated with greater increases in leader task performance (i.e. effective decisionmaking, taking calculated risks, and setting goals).

With regard to the impact of the dark side traits on leader development, however, there is no empirical literature to call on. However, a number of theorists have weighed in on possible avenues for coaching leaders exhibiting traits from the dark side. Brookmire (2007) proposes that practitioners begin with a $360^{\circ}$ assessment to evaluate strengths and weaknesses and to establish a basis for coaching. This is followed up by determining coachability based on personality and abilities, immediately implanting a program to eliminate destructive behaviors, and then setting up a maintenance program to ensure that the target does not regress. Interestingly, Brookmire concedes that it is unlikely that traits associated with derailment can be turned into strengths, so the best bet is to try to limit their negative impact. Cavanagh (2005) makes the argument that the presence of Axis 2 personality disorders can be disruptive to executive coaching and that coaches should be sensitive to the presence of traits that may cause derailment. Nelson and Hogan (2009) argue that leader development interventions should be tailored to the individual's weaknesses to ensure that the development process itself is not derailed. 
On the whole, however, specific suggestions as to which traits are most closely linked with derailment, which are the hardest to overcome, and what procedures are best suited to counteracting them in a leadership intervention are largely lacking. The consensus opinion, however, seems to be that higher levels of subclinical traits are likely to be associated with low performance and problems with training. Based on DSM-IV (American Psychiatric Association, 1994) parameters, for example, we would expect that a leader scoring highly on the HDS Skeptical scale (DSM-IV Paranoid) would be less prone to psychologically engage in developmental experiences. Skeptical leaders would be cynical, distrustful, overly sensitive to criticism, and skeptical of others' true intentions and thus highly unlikely to trust their leader developers/trainers and would likely question the validity of developmental programs. Further as they are sensitive to criticism, we would expect skeptical leaders to have more of an entity approach and performance goal orientation as noted earlier and thus be less open to change (Robins et al., 2005) and less developmentally ready (Hannah \& Avolio, 2010). Similarly, we would expect that a leader with excessively high Imaginative scores (DSM-IV Schizotypal; as noted by acting and thinking in unusual ways) may have difficulty in a leader development program. This would likely be more evident in a program attempting to develop a normative model of leadership, where the leader's "unusual" thoughts and behaviors may make it difficult for him or her to understand or accept the model being taught and to replicate the expected behaviors. Consequently, we hypothesize:

Hypothesis 2. Higher levels of subclinical traits will have a negative relationship with initial standing on leader development variables (i.e., baseline levels).

Hypothesis 3. Higher levels of subclinical traits will have a negative relationship with rates of leader development over time.

\section{The present study}

The present study tracks a cohort of U.S. Army officer cadets from West Point, the United States Military Academy (USMA) from Year 2 through Year 4 of their 4-year program. The USMA is a particularly interesting site to explore the nature of leader development for a number of reasons. The mission of West Point is to "Educate, train, and inspire the Corps of Cadets so that each graduate is a commissioned leader of character committed to the values of duty, honor, country; and prepared for a career of professional excellence and service to the Nation as an officer in the United States Army" (United States Military Academy, 2009, p. VI). The West Point system for leader development (United States Military Academy, 2009, p. 13) includes five components: 1) increase cadet's readiness for development, 2) provide leader development experiences (inclusive of challenge, assessment, and support), 3) offer guided reflection, 4) provide new knowledge and capacities, and 5) conduct development over time. It is the first element that we will focus on in the present study; to assess how subclinical personality traits may influence readiness and moderate leader development over time.

The West Point experience is intense and immersive, 24 hours a day, 7 days a week, where cadet development is planned by dedicated cadre using the five elements of the system above. Some representative components of the leader development system we propose will accelerate leader development in support of Hypothesis 1 follow. First, the Corps of Cadets leads itself (i.e., cadets lead other cadets) under the mentorship of cadre. Each cadet is required to assume progressive leadership positions in the corps of cadets over their 2 nd through 4 th years and lead other cadets through both administrative duties as well as tactical training. In their 2nd and 3rd years cadets perform duties as non-commissioned officers (e.g., squad leader or platoon sergeant) and in their 4th year serve as officers (e.g., platoon, company, or battalion commander). Coupled with these mastery experiences, cadets receive regular counseling from both their direct as well as indirect leaders in the cadet chain of command, and are also closely monitored by USMA training cadre "tactical officers" who provide regular developmental feedback through counseling sessions. Besides these multiple sources of unstructured feedback, a key mechanism for structured feedback is the organization's Periodic Development Review (PDR; the primary outcome variable in this study described in the Methods section), a 360 institutional assessment tool which serves as a formal source of feedback to inform each cadet on how their development is progressing on key facets held important by the institution, as rated by their leaders, peers, and followers. It is the policy of the academy that each cadet be counseled in person by their direct leader on their PDR scores and creates a development program to sustain the strengths and mitigate the weaknesses noted.

Thus each cadet not only experiences multiple progressive leadership mastery experiences, but also receives regular formal and informal multi-source, multi-level feedback on their development. Such feedback represents one of the most widely used and accepted methods of leader development (Brett \& Atwater, 2001; Day, 2001). Although feedback has been demonstrated to be quite effective (Atwater, Roush, \& Fischthal, 1995; Seifert, Yukl, \& McDonald, 2003), prior research also indicates that its effectiveness can be moderated by recipient personality characteristics such as cynicism (Atwater, Waldman, Atwater, \& Cartier, 2000) and overconfidence (Cannon \& Witherspoon, 2005), both of which are closely related to subclinical traits.

Cadets also conduct intense extended tactical training each summer and on drill weekends where they lead their units through physically and mentally challenging tactical exercises (e.g., raids, ambushes, mountaineering, or long-range movements). These difficult experiences provide "jolts" or "crucibles" that can enhance learning and self-awareness and accelerate development (Day et al., 2009; Roberts, Dutton, Spreitzer, Heaphy, \& Quinn, 2005).

Additionally, to provide the knowledge required to guide and inform their leadership mastery experiences, all cadets participate in mandatory leadership classes over their four years at the Academy. Each of the four years they attend military development classes that teach them the principles of officership and of leading soldiers. Further, each year all cadets attend mandatory professional military ethic education classes where they discuss character-based leadership principles and aspects of 
social and interpersonal skills with assigned mentors from the staff and faculty. In addition, in their third year each cadet attends a theory-based course titled military leadership which provides the theoretical basis for leadership, such as transformational leadership and leader-member exchange theories.

Cadets also conduct numerous self-reflection and self-awareness exercises throughout their program that supplement their multisource feedback. For example, in their first year all cadets take various standardized psychological batteries and receive personalized reports which they then discuss with instructors in a basic psychology class which is required of all cadets. In their military leadership course in their 3rd year, cadets are also required to write a paper outlining their vision of themselves as an ideal leader, and also a paper outlining their leadership philosophy; and discuss those papers with their military instructor. Such reflection on the "possible self" can serve to motivate and direct development (Roberts et al., 2005).

Finally, a major emphasis of USMA is the importance of mentors. The predominance of faculty at the academy are military officers who were selected amongst their peers by a selection board as being high performing officers, and the vast majority of these officers have recent combat leadership experience, making them exemplar role models. Further, classes at USMA are capped at 16 cadets per instructor in order to maximize interaction with cadets, and all USMA faculty are personally evaluated on how well they conduct cadet development and are expected to mentor cadets both in and outside the classroom on military leadership.

The present study makes use of external development ratings using the PDR. This measure was developed by the institution specifically to measure cadets' development on areas of military leadership competence (e.g., officership) and character (e.g., sense of duty). This is done as noted above, for example, through military development and professional military ethics classes, respectively. While the PDR is used specifically to assess development and drive feedback and counseling, the academy maintains separate systems to rate cadet performance.

To the best of our knowledge, the present study represents the first multi-wave, multi-source, multi-year investigation of the role of personality in a leader development program. Moreover, it represents the largest sample study to date of the relationship between subclinical traits and leader effectiveness.

\section{Methods}

\subsection{Participants}

The sample consisted of 919 cadets. The mean age of participants was 20.68 years ( $\mathrm{sd}=1.06$ years). Eighty-one percent ( $81 \%$ ) were male. Ethnic breakdowns were as follows: 74\% Caucasian, 8\% Hispanic/Latino, 8\% African-America, 6\% Asian, and 3\% from other ethnic backgrounds. All data were procured from institutional archives.

\subsection{Measures}

\subsubsection{Hogan development survey}

The HDS is a commercial instrument. Information regarding the norms, reliability, and validity of the HDS is available in the user's manual (Hogan \& Hogan, 1997). See Table 1 for a description of the dimensions assessed with the HDS. The HDS consists of 168 statements that respondents indicate they "agree" or "disagree" with. Reported reliabilities for these scales range from .50 for Dutiful to .78 for Excitable. Sample items include "I don't mind being told what to do" (Dutiful), "Some laws were just meant to be broken" (Mischievous), and "I wish I could be more assertive" (Cautious).

\subsubsection{Periodic developmental reviews}

The dependent measures were the cadets' Periodic Developmental Review reports (PDRs) completed in the second, third, and fourth years of training at USMA. The PDRs examined here were administered near the end of the Fall semester of each year. For standardization, the PDRs begin with the cadets' second year because that was when the PDR instrument replaced a previous developmental review tool.

The 46-item PDR instrument was filled out by the cadets' immediate supervisor(s) in the chain-of-command. The PDR consists of 12 major subfacets that consist of dimensions of developed character and capabilities seen by West Point as important to leadership in the military context. A confirmatory factor-analysis of the PDR found good fit for the theoretical model when the PDR was divided into a general factor and 12 primary factors, which were orthogonal to the general factor and to each other $\left(\chi^{2}=62,561, \mathrm{df}=1032, \mathrm{CFI}=.92, \mathrm{NNFI}=.92, \mathrm{RMSEA}=.05, \mathrm{SRMR}=.04\right)$.

The items for each of the 12 primary dimensions were averaged to produce PDR subscales. The PDR facets used were Judgment (7 items, e.g., "Demonstrate sound judgment, reasoning and thinking”), Officership (3 items, e.g.,"Coach, teach and train subordinates"), Interpersonal Fairness (4 items, e.g.,"Interact with others with fairness and dignity"), Communication Skill (2 items, e.g.,"Speak clearly and effectively”), Response to Feedback (3 items, e.g.,"Work to improve self or unit, based on feedback”), Sense of Duty ( 5 items, e.g.,"Accept assigned duties willingly”), Fitness (2 items, e.g.,"Demonstrate an appropriate level of physical fitness and mental toughness"), Courage (4 items, e.g.,"Maintain composure under stress"), Conduct (4 items, e.g.,"Demonstrate mature, responsible behavior in social and professional environments"), Unselfishness (3 items, e.g.,"Put the good of the group ahead of his/her own self-interest"), Army Values (4 items, e.g.,"Becoming the person the Army expects him/her to be"), and Conscientiousness (6 items, e.g.,"Pay appropriate attention to detail”).

All PDR items are rated on a 7 point scale ranging from 1 ("never") to 7 ("always") representing the frequency with which the rated leader exhibits that behavior. Cadets were rated by numerous individuals in their chain of command. Each cadet was rated by 
1 to 6 raters ( $m e a n=2.64$ ). The average intra-class correlation for the multiple ratings at each time point for the general factor was .60 , indicating that it was appropriate to aggregate ratings.

\subsection{Descriptive statistics}

Means, standard deviations, and average alphas for the chain of command PDR ratings are presented in Table 2 . As shown there was a general trend of positive development across each of the 12 facets. Correlations between the Hogan Development Survey dimensions and these development facets Year 2 to Year 4 are provided in Table 3.

\subsection{Analytical strategy}

The analyses presented in this paper use a multilevel random coefficients approach to model individual growth curves (e.g., Bliese \& Ployhart, 2002). The basic model is as follows. Within-individual variability is modeled with the regression equation:

$$
Y_{\mathrm{ij}}=B_{0 \mathrm{j}}+B_{1 \mathrm{j}} T I M E_{\mathrm{i}}+r_{\mathrm{ij}}
$$

where $\mathrm{TIME}_{\mathrm{i}}$ is a linear index for the time of measurement $I$, of outcome $Y$, for individual $J$, and the between-persons variation is described by the following regression equations:

$$
\begin{aligned}
& B_{0 \mathrm{j}}=\gamma_{00}+U_{0 \mathrm{j}} \\
& B_{1 \mathrm{j}}=\gamma_{10}+U_{1 \mathrm{j}} .
\end{aligned}
$$

Eqs. (2) and (3) allow for individual variability in the regression coefficients, $B_{0}$ and $B_{1}$. Variability in the regression coefficients allows for individual differences in intercepts $\left(B_{0}\right)$ and slopes $\left(B_{1}\right)$, meaning that different individuals may start at different levels and change from that starting point at different rates (even in different directions).

Furthermore, variability in development trajectories can be explained by adding predictors at the between-individuals level, such that Eq. (2) becomes $B_{0 j}=\gamma_{00}+\gamma_{01} Z_{j}+U_{0 j}$ and Eq. (3) becomes $B_{0 j}=\gamma_{10}+\gamma_{11} Z_{j}+U_{0 j}$, where $Z_{j}$ is individual J's standing on some predictor variable, such as a personality trait.

\subsection{Exploratory analyses}

First, we examined change in the PDR facets by regressing the Year 4 scores onto Year 2 scores, demographic controls (age and sex) and the HDS dimensions. Incorporating the Year 2 scores as predictors controls for individual differences in initial standing on the variable (i.e., their intercept). The HDS dimensions are therefore predicting the residualized change in the PDR facet. Due to missing data on the demographics, the sample size for these models is a maximum of 704 cadets. These analyses were conducted in two steps: Step 1 included the Year 2 scores and the demographic controls and Step 2 added the HDS dimensions. Results are presented in Table 4. The Control R-sq values indicate the $R^{2}$ value for step 1 , with $\Delta \mathrm{R}$-sq representing the change in $R^{2}$ associated with step 2. As shown the HDS facets together explained between 11 and $17 \%$ of the variance in the PDR dimensions. The smallest $F$-value for these tests was for Communication skill $\left(F_{(10,654)}=7.93, p<.0001\right)$.

When viewing the individual HDS facet beta coefficients shown in Table 4 it is important to note that they are unstandardized, meaning that the PDR facet increases by beta for each unit increase in the HDS dimension, controlling for the other predictors in

\begin{tabular}{|c|c|c|c|c|c|c|c|}
\hline \multirow[b]{2}{*}{ DV } & \multicolumn{2}{|c|}{ Year 2} & \multicolumn{2}{|c|}{ Year 3} & \multicolumn{2}{|c|}{ Year 4} & \multirow[b]{2}{*}{ Alpha } \\
\hline & Mean & $S D$ & Mean & $S D$ & Mean & $S D$ & \\
\hline Judgment & 5.61 & 0.76 & 6.28 & 0.60 & 6.41 & 0.55 & .91 \\
\hline Communication & 6.20 & 0.75 & 6.33 & 0.65 & 6.50 & 0.55 & .85 \\
\hline Leadership & 6.21 & 0.73 & 6.29 & 0.65 & 6.41 & 0.63 & .84 \\
\hline Fairness & 5.20 & 0.92 & 6.38 & 0.57 & 6.51 & 0.52 & .83 \\
\hline Sense of Duty & 5.59 & 0.58 & 6.34 & 0.61 & 6.46 & 0.57 & .87 \\
\hline Response to Feedback & 5.30 & 0.81 & 6.24 & 0.67 & 6.42 & 0.59 & .81 \\
\hline Courage & 4.84 & 1.24 & 6.24 & 0.62 & 6.38 & 0.60 & .84 \\
\hline Conduct & 5.03 & 1.01 & 6.37 & 0.61 & 6.48 & 0.56 & .81 \\
\hline Unselfishness & 5.34 & 1.36 & 6.34 & 0.62 & 6.46 & 0.58 & .86 \\
\hline Army Values & 6.03 & 1.07 & 6.28 & 0.93 & 6.41 & 0.90 & .83 \\
\hline Conscientiousness & 5.77 & 0.80 & 6.23 & 0.64 & 6.37 & 0.61 & .89 \\
\hline Fitness & 6.33 & 0.69 & 6.39 & 0.69 & 6.53 & 0.64 & .93 \\
\hline General factor & 5.61 & 0.73 & 6.28 & 0.69 & 6.43 & 0.59 & .98 \\
\hline
\end{tabular}

Table 2

Descriptive statistics for chain-of-command development ratings.

Note. Alpha is the average alpha for all 3 times. 
Table 3

Hogan dimensions and chain-of-command development rating correlations.

\begin{tabular}{|c|c|c|c|c|c|c|c|c|c|c|c|c|}
\hline \multirow{2}{*}{$\frac{\text { HDS Facets }}{\text { Year } 2}$} & \multicolumn{12}{|c|}{ PDR development dimensions } \\
\hline & Judge & Comm & Officer & Fair & Duty & Feedback & Courage & Conduct & Unselfish & Values & Consc & Fit \\
\hline Excitable & 0.10 & 0.07 & -0.01 & 0.13 & 0.03 & 0.14 & 0.07 & 0.07 & 0.03 & 0.07 & 0.08 & 0.05 \\
\hline Skeptical & 0.03 & 0.05 & -0.08 & 0.07 & -0.06 & 0.12 & 0.05 & 0.03 & -0.01 & 0.02 & 0.07 & -0.01 \\
\hline Cautious & 0.11 & 0.08 & 0.05 & 0.15 & 0.06 & 0.11 & 0.05 & 0.04 & 0.07 & 0.09 & 0.10 & 0.03 \\
\hline Reserved & -0.04 & 0.04 & -0.06 & -0.02 & -0.02 & 0.00 & -0.03 & 0.03 & -0.05 & 0.03 & 0.01 & -0.02 \\
\hline Leisurely & -0.02 & 0.04 & 0.03 & -0.03 & 0.09 & 0.03 & -0.03 & -0.03 & -0.07 & -0.04 & 0.07 & 0.01 \\
\hline Bold & 0.05 & -0.04 & -0.07 & 0.05 & 0.04 & 0.11 & 0.05 & 0.11 & -0.01 & -0.03 & -0.01 & 0.06 \\
\hline Mischievous & 0.10 & 0.06 & -0.02 & 0.10 & 0.10 & 0.06 & 0.11 & 0.11 & 0.08 & 0.02 & 0.05 & 0.10 \\
\hline Colorful & 0.04 & 0.02 & 0.04 & 0.04 & 0.08 & 0.09 & 0.11 & 0.04 & 0.07 & -0.01 & 0.02 & 0.08 \\
\hline Imaginative & -0.07 & -0.09 & -0.10 & -0.06 & 0.02 & -0.04 & -0.04 & -0.02 & -0.04 & -0.18 & -0.09 & -0.07 \\
\hline Diligent & -0.03 & -0.10 & -0.06 & 0.00 & -0.03 & 0.00 & 0.01 & 0.00 & -0.03 & -0.06 & -0.01 & -0.07 \\
\hline Dutiful & 0.05 & 0.07 & 0.09 & 0.00 & -0.01 & 0.04 & 0.03 & 0.02 & 0.03 & 0.03 & 0.06 & 0.06 \\
\hline Year 3 & Judge & Comm & Officer & Fair & Duty & Feedback & Courage & Conduct & Unselfish & Values & Consc & Fit \\
\hline Excitable & 0.04 & 0.01 & -0.01 & 0.00 & -0.01 & -0.04 & -0.06 & -0.04 & 0.08 & 0.07 & 0.03 & -0.03 \\
\hline Skeptical & -0.06 & -0.09 & -0.12 & -0.13 & -0.09 & -0.10 & -0.10 & -0.14 & 0.01 & -0.10 & -0.07 & -0.13 \\
\hline Cautious & -0.03 & -0.09 & -0.11 & -0.02 & -0.09 & -0.15 & -0.15 & -0.04 & 0.01 & 0.01 & -0.08 & -0.13 \\
\hline Reserved & -0.19 & -0.24 & -0.22 & -0.17 & -0.27 & -0.29 & -0.17 & -0.16 & -0.14 & -0.09 & -0.21 & -0.28 \\
\hline Leisurely & -0.10 & -0.16 & -0.07 & -0.07 & -0.12 & -0.14 & -0.07 & -0.01 & -0.07 & -0.08 & -0.08 & -0.12 \\
\hline Bold & 0.01 & 0.02 & 0.04 & 0.00 & 0.03 & 0.14 & 0.08 & 0.02 & 0.06 & 0.02 & 0.11 & 0.03 \\
\hline Mischievous & 0.01 & 0.00 & 0.03 & -0.09 & -0.03 & 0.09 & -0.01 & -0.03 & -0.07 & -0.17 & 0.01 & 0.02 \\
\hline Colorful & -0.01 & 0.13 & 0.03 & -0.04 & -0.01 & 0.12 & 0.01 & -0.08 & -0.09 & -0.17 & 0.02 & 0.01 \\
\hline Imaginative & -0.14 & -0.19 & -0.21 & -0.18 & -0.20 & -0.17 & -0.21 & -0.21 & -0.16 & -0.13 & -0.18 & -0.17 \\
\hline Diligent & 0.19 & 0.16 & 0.27 & 0.24 & 0.27 & 0.16 & 0.22 & 0.26 & 0.28 & 0.23 & 0.25 & 0.21 \\
\hline Dutiful & -0.07 & 0.06 & -0.02 & -0.01 & 0.03 & 0.03 & -0.02 & -0.01 & 0.01 & 0.01 & -0.01 & 0.01 \\
\hline Year 4 & Judge & Comm & Officer & Fair & Duty & Feedback & Courage & Conduct & Unselfish & Values & Consc & Fit \\
\hline Excitable & -0.04 & 0.04 & 0.02 & -0.03 & -0.04 & -0.03 & -0.04 & -0.06 & -0.02 & -0.04 & -0.01 & -0.10 \\
\hline Skeptical & -0.20 & -0.14 & -0.19 & -0.18 & -0.21 & -0.19 & -0.20 & -0.14 & -0.19 & -0.15 & -0.20 & -0.19 \\
\hline Cautious & 0.11 & 0.13 & 0.02 & 0.10 & 0.12 & 0.09 & 0.05 & 0.07 & 0.11 & 0.19 & 0.02 & -0.09 \\
\hline Reserved & -0.01 & 0.02 & -0.08 & -0.01 & -0.05 & -0.03 & -0.06 & 0.01 & -0.05 & 0.02 & -0.06 & -0.09 \\
\hline Leisurely & -0.01 & -0.02 & -0.06 & -0.02 & -0.08 & -0.01 & -0.06 & 0.01 & -0.07 & -0.01 & -0.08 & -0.03 \\
\hline Bold & 0.07 & 0.05 & 0.08 & 0.11 & 0.03 & 0.05 & 0.06 & 0.08 & 0.02 & 0.09 & 0.04 & 0.04 \\
\hline Mischievous & -0.11 & -0.02 & -0.05 & -0.05 & -0.12 & -0.10 & -0.09 & -0.14 & -0.16 & 0.03 & -0.09 & -0.01 \\
\hline Colorful & 0.04 & 0.05 & 0.09 & 0.03 & 0.05 & 0.02 & 0.08 & 0.01 & 0.03 & 0.07 & 0.09 & 0.17 \\
\hline Imaginative & -0.24 & -0.25 & -0.09 & -0.25 & -0.23 & -0.24 & -0.23 & -0.22 & -0.27 & -0.21 & -0.27 & -0.28 \\
\hline Diligent & 0.19 & 0.15 & 0.19 & 0.19 & 0.21 & 0.13 & 0.17 & 0.23 & 0.11 & 0.12 & 0.17 & 0.01 \\
\hline Dutiful & 0.19 & 0.16 & 0.18 & 0.18 & 0.23 & 0.21 & 0.20 & 0.13 & 0.12 & 0.14 & 0.16 & 0.08 \\
\hline
\end{tabular}

Note. Judge = Judgment; Comm = Communication; Officer = Officership; Fair = Fairness; Duty = Sense of Duty; Feedback = Response to Feedback; Unselfish = Unselfishness; Values $=$ Army Values; Consc $=$ Conscientiousness; Fit $=$ Fitness. Correlations above .065 are significant $p<.05$.

the model, including PDR facet levels at time 1. As unstandardized betas, they are in the 7-point scale of the PDR facets. Note also that the individual betas are small, but additive as reflected in the $R^{2}$ scores. Also, the betas for the time 1 facets are rather small and the intercepts are quite large, reflecting the restricted variance of the PDR facets.

In these analyses, several HDS dimensions emerged as consistent predictors of change in PDR facets over the final 2 years of the study. Imaginative was the most consistent predictor and showed significant negative relationships with 10 facets. Skeptical and Diligent each predicted 9 facets, but in opposite directions with Diligent representing a positive predictor of development and Skeptical being negatively related. Cautious, Bold, Colorful, and Dutiful each predicted positive development in at least 4 PDR facets. Leisurely negatively related to development in at least 4 PDR facets. Mischievous and Excitable both showed mixed effects and little relationship to leader development over time.

\subsection{Individual growth models}

The preceding analyses give an impression of how these personality characteristics may relate to change and learning, however, they do not model individual-level growth. So, we followed those analyses with individual growth models, as depicted in Eqs. (1) to (3). We focused on those HDS dimensions that emerged as consistent predictors of change in the exploratory analyses: Skeptical, Diligent, Imaginative, Cautious, Leisurely, Bold, and Dutiful.

The following analyses follow the approach outlined by Bliese and Ployhart (2002); and Bliese (2002). First, the plausibility of applying random coefficients models was addressed for each PDR facet. Table 5 presents the results of these analyses. In the table, Fixed Effect ANOVA models refer to a model with only a fixed intercept (mean), fitted with generalized least squares. To determine whether there is significant variance in intercepts between individuals, a model with random intercepts (Mixed Effect ANOVA) 
Table 4

Regression analyses of Year 4 PDR facet scores.

\begin{tabular}{|c|c|c|c|c|c|c|c|c|c|c|c|c|}
\hline Variable & Judge & Comm & Officer & Fair & Duty & Feedback & Courage & Conduct & Unselfish & Values & Consc & Fit \\
\hline Intercept & 5.43 & 5.60 & 4.95 & 5.53 & 5.55 & 5.95 & 5.52 & 5.89 & 6.35 & 4.48 & 5.61 & 6.22 \\
\hline Time 1 PDR & 0.08 & 0.03 & 0.10 & 0.04 & 0.11 & 0.02 & 0.04 & 0.06 & 0.04 & 0.09 & 0.11 & 0.05 \\
\hline Age & 0.01 & 0.02 & 0.01 & 0.02 & 0.00 & 0.01 & 0.01 & 0.01 & 0.01 & 0.02 & 0.01 & 0.00 \\
\hline Sex & 0.10 & 0.06 & 0.06 & -0.07 & 0.09 & 0.08 & 0.11 & 0.05 & 0.18 & 0.47 & 0.11 & 0.16 \\
\hline Skeptical & -0.03 & -0.02 & -0.05 & -0.03 & -0.03 & -0.03 & -0.03 & -0.02 & -0.04 & -0.03 & -0.05 & -0.03 \\
\hline Excitable & 0.00 & 0.01 & 0.03 & 0.00 & 0.00 & 0.01 & 0.00 & -0.01 & 0.00 & -0.04 & 0.02 & 0.00 \\
\hline Cautious & 0.03 & 0.03 & 0.00 & 0.03 & 0.04 & 0.03 & 0.03 & 0.03 & 0.05 & 0.12 & 0.02 & 0.00 \\
\hline Reserved & 0.01 & 0.00 & 0.00 & 0.01 & 0.00 & 0.02 & 0.01 & 0.02 & 0.00 & 0.01 & 0.01 & 0.03 \\
\hline Leisurely & 0.00 & -0.02 & -0.03 & 0.00 & -0.03 & 0.00 & -0.01 & 0.00 & -0.03 & -0.03 & -0.02 & 0.01 \\
\hline Bold & 0.03 & 0.02 & 0.03 & 0.05 & 0.02 & 0.04 & 0.03 & 0.03 & 0.03 & 0.04 & 0.02 & 0.01 \\
\hline Mischievous & -0.01 & 0.02 & 0.00 & 0.02 & -0.01 & 0.00 & 0.00 & -0.03 & -0.03 & 0.05 & -0.01 & 0.01 \\
\hline Colorful & 0.02 & 0.01 & 0.02 & 0.01 & 0.03 & 0.01 & 0.02 & 0.02 & 0.02 & 0.03 & 0.03 & 0.05 \\
\hline Imaginative & -0.05 & -0.06 & -0.01 & -0.07 & -0.05 & -0.06 & -0.06 & -0.05 & -0.06 & -0.08 & -0.06 & -0.09 \\
\hline Diligent & 0.03 & 0.02 & 0.05 & 0.03 & 0.03 & 0.01 & 0.03 & 0.04 & 0.01 & 0.03 & 0.03 & 0.00 \\
\hline Dutiful & 0.02 & 0.01 & 0.02 & 0.03 & 0.02 & 0.04 & 0.03 & 0.01 & 0.00 & 0.01 & 0.01 & 0.01 \\
\hline R-sq & .18 & .15 & .15 & .18 & .19 & .14 & .16 & .14 & .17 & .22 & .18 & .16 \\
\hline Adj. R-sq. & .16 & .13 & .13 & .16 & .17 & .13 & .15 & .13 & .16 & .21 & .17 & .14 \\
\hline Control R-sq & .04 & .04 & .03 & .03 & .02 & .01 & .03 & .01 & .03 & .06 & .05 & .02 \\
\hline$\Delta \mathrm{R}-\mathrm{sq}$ & .14 & .11 & .12 & .15 & .17 & .13 & .13 & .13 & .14 & .16 & .13 & .14 \\
\hline
\end{tabular}

Note. Judge = Judgment; Comm = Communication; Officer = Officership; Fair = Fairness; Duty = Sense of Duty; Feedback = Response to Feedback; Unselfish = Unselfishness; Values = Army Values; Consc = Conscientiousness; Fit = Fitness.

Regression coefficients in bold are statistically significant at the .05 level. All coefficients are unstandardized betas.

was fitted using a linear mixed effect model (using Eqs. (1) and (2)). A significant likelihood ratio test comparing these models indicated that random intercepts for the PDR facet were supported.

The intraclass correlation (ICC) indicates how much of the total variation was accounted for by the random intercept $(\mathrm{ICC}=\operatorname{VAR}($ intercepts $) /(\operatorname{VAR}($ intercepts $)+\operatorname{VAR}($ residuals $)))$. The variance of the intercept is variance attributable to differences between individuals; the variance of the residual cannot be explained by differences between individuals, but may be explained by systematic changes over time within the individual. Therefore, a low ICC indicates that most of the variance is within, rather than between, persons (Singer \& Willett, 2003).

Next, a model with a fixed effect for time was fitted. In this case, each cadet's score for the PDR facet at each time point was regressed onto a linear index of time (coded as 0,1,2, etc.), as shown in Eq. (1). Models were compared using likelihood ratio tests. The likelihood ratio is distributed as a $\chi^{2}$ with degrees of freedom equal to the difference in model degrees of freedom between the two models being compared. A significant likelihood ratio comparing the fixed effect model to the Mixed Effect ANOVA indicated a significant mean trend, i.e., the average tendency in the sample was for cadets to improve across all PDR facets. The fixed effect estimates in Table 5 are again unstandardized betas, meaning that the PDR facet changes by beta with each time step. These betas are in the PDR facets' 7-point scale.

Following that, a model with a random effect for time was compared to the previous model with only a fixed effect for time (Eqs. (1) through (3)). The fixed effect captured only the mean trajectory for the sample, the random effect allowed this trajectory to vary over individuals. For instance, some cadets may have shown change consistent with the mean trend, some may have developed more or less quickly, some may not have changed at all, and some may even have changed downward, in the opposite direction of the mean trend. A significant likelihood ratio test for this model comparison indicated that such a random effect significantly improved the overall fit of the model. The random effect estimates in Table 5 are standard deviations.

The ICCs for all developmental domains showed that there is substantial within-person variance, but some coherence over time (all ICCs except for Fairness are greater than 13 but less than .22; see Singer, 1998). Note that all PDR facets, except for Officership showed significant fixed and random effects for time. This means that there was an average tendency for cadets to improve over the two-year period, as well as individual differences in rate of improvement.

The presence of random effects allowed us to next test whether there were person-level moderators of these developmental trends, using the Hogan Development Survey scales. In general, we tested those HDS dimensions that appeared to be the most consistent predictors of change in the regression analyses. Table 6 presents the results of these models.

In Table 6, Model 1 refers to the unconditional (without the HDS entered as predictors) growth model for each PDR facet, and Model 2 refers to a model using HDS dimensions to predict individual differences in slopes and/or intercepts. For each of the developmental outcomes, except for Values, the addition of the HDS dimensions to the model resulted in significantly better model fit, as indicated by significant likelihood ratio tests. This indicated that these personality traits were useful in explaining some of the between-person differences in developmental trajectories. The "Pseudo- $R^{2}$ " indicates the percentage of variance in slopes that was explained by the HDS dimensions. This means that individual differences in development were partially accounted for by individual differences in HDS dimensions. 
Table 5

Individual growth models for chain-of-command rated development facets.

\begin{tabular}{|c|c|c|c|c|c|}
\hline DV & Model & logLike & LR & $\mathrm{p}$ & Effect \\
\hline Judgment & Fixed effects ANOVA & -1739.30 & & & \\
\hline \multirow[t]{3}{*}{$\mathrm{ICC}=.13$} & Mixed effects ANOVA & -1726.40 & 25.84 & $<.0001$ & \\
\hline & Fixed effect-time & -1665.72 & 121.42 & $<.0001$ & .24 \\
\hline & Random effect-time & -1653.37 & 24.70 & $<.0001$ & .24 \\
\hline Communication skill & Fixed effects ANOVA & -1729.70 & & & \\
\hline \multirow[t]{3}{*}{$\mathrm{ICC}=.11$} & Mixed effects ANOVA & -1720.10 & 19.14 & $<.0001$ & \\
\hline & Fixed effect-time & -1697.51 & 45.26 & $<.0001$ & .15 \\
\hline & Random effect-time & -1682.12 & 30.76 & $<.0001$ & 0.24 \\
\hline Officership & Fixed effects ANOVA & -1829.30 & & & \\
\hline \multirow[t]{3}{*}{$\mathrm{ICC}=.18$} & Mixed effects ANOVA & -1810.30 & 38.07 & $<.0001$ & \\
\hline & Fixed effect-time & -1799.31 & 21.97 & $<.0001$ & .11 \\
\hline & Random effect-time & -1798.29 & 1.83 & 0.40 & .17 \\
\hline Fairness & Fixed effects ANOVA & -1824.8 & & & \\
\hline \multirow[t]{3}{*}{$\mathrm{ICC}=.00$} & Mixed effects ANOVA & -1821.5 & 6.57 & 0.01 & \\
\hline & Fixed effect-time & -1708.05 & 226.95 & $<.0001$ & .37 \\
\hline & Random effect-time & -1652.67 & 110.76 & $<.0001$ & .37 \\
\hline Sense of Duty & Fixed effects ANOVA & -1767.90 & & & \\
\hline \multirow[t]{3}{*}{$\mathrm{ICC}=.15$} & Mixed effects ANOVA & -1752.40 & 31.17 & $<.0001$ & \\
\hline & Fixed effect-time & -1688.42 & 127.88 & $<.0001$ & .25 \\
\hline & Random effect-time & -1684.59 & 7.65 & 0.02 & .14 \\
\hline Response to Feedback & Fixed effects ANOVA & -1947.5 & & & \\
\hline \multirow[t]{3}{*}{$\mathrm{ICC}=.13$} & Mixed effects ANOVA & -1935.00 & 25.06 & $<.0001$ & \\
\hline & Fixed effect-time & -1839.22 & 191.48 & $<.0001$ & .34 \\
\hline & Random effect-time & -1815.62 & 47.19 & $<.0001$ & .33 \\
\hline Courage & Fixed effects ANOVA & -2094.30 & & & \\
\hline \multirow[t]{3}{*}{$\mathrm{ICC}=.07$} & Mixed effects ANOVA & -2088.00 & 12.50 & $<0.001$ & \\
\hline & Fixed effect-time & -1972.00 & 232.01 & $<.0001$ & .42 \\
\hline & Random effect-time & -1903.39 & 137.22 & $<.0001$ & .45 \\
\hline Conduct & Fixed effects ANOVA & -1977.00 & & & \\
\hline \multirow[t]{3}{*}{$\mathrm{ICC}=.08$} & Mixed effects ANOVA & -1969.40 & 15.24 & $<.0001$ & \\
\hline & Fixed effect-time & -1861.15 & 216.46 & $<.0001$ & .37 \\
\hline & Random effect-time & -1805.57 & 111.16 & $<.0001$ & .40 \\
\hline Unselfishness & Fixed effects ANOVA & -1997.30 & & & \\
\hline \multirow[t]{3}{*}{$\mathrm{ICC}=.09$} & Mixed effects ANOVA & -1989.30 & 15.94 & $<.0001$ & \\
\hline & Fixed effect-time & -1917.07 & 144.49 & $<.0001$ & .31 \\
\hline & Random effect-time & -1836.53 & 161.08 & $<.0001$ & .45 \\
\hline Values & Fixed effects ANOVA & -2520.40 & & & \\
\hline \multirow[t]{3}{*}{$\mathrm{ICC}=.17$} & Mixed effects ANOVA & -2503.00 & 34.73 & $<.0001$ & \\
\hline & Fixed effect-time & -2492.76 & 20.52 & $<.0001$ & .15 \\
\hline & Random effect-time & -2489.18 & 7.16 & 0.03 & .22 \\
\hline Conscientiousness & Fixed effects ANOVA & -1850.20 & & & \\
\hline \multirow[t]{3}{*}{$\mathrm{ICC}=.22$} & Mixed effects ANOVA & -1822.20 & 55.97 & $<.0001$ & \\
\hline & Fixed effect-time & -1780.96 & 82.41 & $<.0001$ & .21 \\
\hline & Random effect-time & -1775.45 & 11.03 & $<0.001$ & .20 \\
\hline Fitness & Fixed effects ANOVA & -1888.40 & & & \\
\hline \multirow[t]{3}{*}{$\mathrm{ICC}=.24$} & Mixed effects ANOVA & -1856.20 & 64.4 & $<.0001$ & \\
\hline & Fixed effect-time & -1844.52 & 23.38 & $<.0001$ & .11 \\
\hline & Random effect-time & -1843.00 & 3.04 & 0.21 & .12 \\
\hline
\end{tabular}

Note. Fixed effect estimates are unstandardized betas, random effect estimates are standard deviations.

\section{Discussion}

The present study set out to assess whether personality, and in particular subclinical personality traits, are important factors in determining the responsiveness of individuals to a leader development program. We utilized a large-scale sample of cadets in a military academy to evaluate the relative impact of subclinical personality traits on chain-of-command ratings of leader development. Using a multi-year, multi-wave format, we showed that leaders respond positively to regularly administered multi-source feedback reports. Moreover, that they continue to show increases in leader development over a three year period.

We first hypothesized that the cadets would show positive changes over time in terms of leader development. The evidence indicates that this hypothesis was largely confirmed with each of the 12 leader development dimensions showing increases over time.

Our second hypothesis concerned the relative impact of the subclinical dimensions on leader development. On the whole, our results suggest that subclinical traits were important moderators of the rate of leader development. The subclinicals assessed in the current study accounted for 11-17\% of the variance in the changes in leader development across three years. These findings are only slightly smaller in magnitude than the relationships found between Big Five personality traits and leader effectiveness and 
Table 6

Individual growth models for chain-of-command ratings of performance.

\begin{tabular}{|c|c|c|c|c|c|c|}
\hline PDR facet & & LogLike & $d f$ & LR & $p$ & Pseudo- $R^{2}$ \\
\hline \multirow[t]{2}{*}{ Judgment } & Model 1 & -1653.37 & 6 & & & \\
\hline & Model 2 & -1620.30 & 11 & 66.14 & $<.0001$ & .03 \\
\hline \multirow[t]{2}{*}{ Communication } & Model 1 & -1682.20 & 6 & & & \\
\hline & Model 2 & -1677.16 & 8 & 10.09 & .01 & .10 \\
\hline \multirow[t]{2}{*}{ Officership* } & Model 1 & -1797.23 & 6 & & & \\
\hline & Model 2 & -1774.17 & 11 & 46.11 & $<.0001$ & .04 \\
\hline \multirow[t]{2}{*}{ Fairness } & Model 1 & -1651.65 & 6 & & & \\
\hline & Model 2 & -1631.37 & 12 & 40.56 & $<.0001$ & .004 \\
\hline \multirow[t]{2}{*}{ Sense of Duty } & Model 1 & -1683.64 & 6 & & & \\
\hline & Model 2 & -1674.60 & 8 & 18.09 & .0001 & .11 \\
\hline \multirow[t]{2}{*}{ Response to Feedback } & Model 1 & -1815.62 & 6 & & & \\
\hline & Model 2 & -1798.26 & 11 & 34.72 & $<.0001$ & .03 \\
\hline \multirow[t]{2}{*}{ Courage } & Model 1 & -1903.32 & 6 & & & \\
\hline & Model 2 & -1897.90 & 8 & 8.83 & .01 & .001 \\
\hline \multirow[t]{2}{*}{ Conduct } & Model 1 & -1804.45 & 6 & & & \\
\hline & Model 2 & -1800.42 & 8 & 8.06 & .02 & .004 \\
\hline \multirow[t]{2}{*}{ Unselfishness } & Model 1 & -1835.57 & 6 & & & \\
\hline & Model 2 & -1814.98 & 10 & 41.17 & $<.0001$ & .04 \\
\hline \multirow[t]{2}{*}{ Army Values } & Model 1 & -2487.43 & 6 & & & \\
\hline & Model 2 & -2486.80 & 10 & 1.26 & 0.87 & .06 \\
\hline \multirow[t]{2}{*}{ Conscientiousness } & Model 1 & -1774.49 & 6 & & & \\
\hline & Model 2 & -1749.36 & 10 & 68.26 & $<.0001$ & .09 \\
\hline \multirow[t]{2}{*}{ Fitness $*$} & Model 1 & -1841.87 & 6 & & & \\
\hline & Model 2 & -1821.28 & 10 & 27.18 & $<.0001$ & .30 \\
\hline
\end{tabular}

Note: $\mathrm{LR}=$ Likelihood ratio.

$*$ The random slope was non-significant, so these tests should be interpreted with caution.

emergence (Judge et al., 2002), but were larger than those found in research linking personality with changes in job performance over time (Thoresen et al., 2004).

Based on prior theory and the experiences of practitioners, we hypothesized negative relationships between the subclinical disorders and leader development over time. With regard to this hypothesis, our results were certainly more ambivalent. While a few HDS dimensions (Skeptical and Imaginative) did show significant, negative relationships with leader development that we had anticipated, a number of others (Cautious, Bold, Colorful, and Dutiful) were found to have positive relationships with leader development over time and across multiple dimensions of leadership. The remaining dimensions had few or inconsistent effects. The results require some explanation. While these findings may seem suggestive of a suppressor effect, we find this explanation unlikely. Not only are the HDS dimensions relatively unrelated, but the consistency of these effects across multiple raters and dimensions seems to indicate that these represent the true relationships.

The answer as to why some subclinical dimensions showed positive effects can be found in a variety of sources. The relatively consistent positive relationship between Dutiful and Diligent and leader development is actually fairly consistent with prior research showing that these dimensions have either a non-significant or positive relationship with leader effectiveness ratings (e.g. Furnham et al., 2009; Lindberg, 2006; Torregiante, 2005). One likely reason for these effects is the substantial positive relationship between Conscientiousness and these traits (Hogan \& Hogan, 1997). Because there is not a measure of Conscientiousness (as a personality trait) in the current study, its positive effects on development may be contaminating the Dutiful and Diligent dimensions and overwhelming their "dark side" effects. Future research will be needed to evaluate whether or not this explanation can inform what is happening. An alternative explanation is that training represents a circumstance where these traits do not function like subclinical traits. For example, Dutiful corresponds to a high need to please others. Individuals with this subclinical trait may be more likely to bend over backwards to meet the expectations of others. In a training setting, it may be difficult to distinguish when this is an appropriate response or not. Another explanation may be the unique military setting, inclusive of intense tactical training exercises and other extreme conditions, which Hannah, Uhl-Bien, Avolio, and Cavarretta (2009) argue creates unique contingencies and causations related to leadership. For example, individuals who comply readily and are detail-oriented may be simply better suited to this context and the typical training methods. It is thus possible that the positive relationship between these traits and leader development is largely context-specific. The same explanation may also explain the positive relationship with the Cautious dimension.

With regard to the positive relationship between Bold, Colorful, and development, some prior theory indicates that this too may not be entirely unexpected. Maccoby (2003) has argued that functional narcissists are often voracious learners who seek out and integrate as much information as they can on subjects which interest them. For example, Napoleon, although not noted as an exceptional student in terms of raw ability, had a fierce appetite for works of military history and philosophy. Likewise, Babiak and Hare (2006) have noted that fellow organizational members often mistake self-enhancing, dramatic, and attention-getting tendencies in leaders for positive qualities such as charisma and self-confidence. This is particularly true when exposure to the target is limited or they are not direct subordinates. 
These mixed findings serve as a reminder that both bright side traits and dark side traits can be effective or ineffective depending on the circumstance and an individual's relative standing on that trait (Judge et al., 2009). Virtually any trait is pathological if taken to an extreme (Miller, Lynam, Widiger, \& Leukefeld, 2001). For example, extreme levels of Conscientiousness can turn into obsessive-compulsive behaviors if not held in check. Likewise, the theory of subclinical traits postulates that they are adaptive in some circumstances or at low levels.

For example, Gable and Dangello (1994) found significant positive relationships between Machiavellianism and unit performance in a study of store managers. Consequently, we need to be aware of when such behaviors are appropriate. In the present study, Mischievous, a trait associated with risk-taking, showed a positive relationship with developing an identity consistent with Army values. This may make sense in the context of a military organization in wartime. A similar finding may be highly unexpected in an accounting firm.

All told, these results suggest that when assessing development, the "dark side" traits may not necessarily be undesired. Some may facilitate while others may impede development. More research across broad contexts is certainly required to assess whether the patterns we found here replicate across contexts.

Although not a major feature of the present study, the results of this study indicate that leader development can persist at significant levels over a long period of time. This finding supports the notion that significant, enduring changes in leadership require more than a short workshop or other low-commitment interventions (Avolio, 2005).

Another relevant result of the present study is to illustrate the power of self-awareness for leader development. The cadets in our sample were not only given repeated reports based on multi-source feedback, but they were also encouraged to become more introspective by taking part in character assessments and engaging in directed discussions concerning how to interpret their scores and improve themselves. On the whole, the USMA leader development program showed that they could take young leaders and make them even better.

\subsection{Implications}

One of the more important implications of the present study is that it not only indicates that personality traits play a significant role in leader development, but also that development itself may persist over multiple years and that the effects of personality on that process and growth trajectories persists over time. The present study also illustrated the importance of going beyond typical assessments of personality (i.e. Big Five) in order to better understand the psychological processes that shape behavior. Importantly, our literature review suggests that this is the first study to assess personality influences on leader development over an extended time.

An important practical implication of this research is that it offers insight into the dynamic relationship between personality and leader development. It suggests that there may be circumstances that determine which personality traits are positively or negatively associated with development. Consequently, with additional research practitioners may be able to tailor executive training programs and leadership interventions to the specific needs of the individual.

In terms of intervention effectiveness, we have also learned a lot about how subclinical traits can inhibit growth, or accelerate it. But how do we deal with the difficult client exhibiting high levels of one or more of these disorders? If subclinical traits have such a negative effect, is there nothing we can do? We categorically reject this notion. Research has demonstrated that even clinical levels of personality disorders can be treated with appropriate methods (Dinglfield, 2004; Leichsenring \& Leibing, 2003). Moreover, time and time again research has demonstrated that personality changes-and it typically changes for the better (Roberts et al. 2008). However, it is also important to remember that personality traits and disorders themselves can moderate responsiveness to particular forms of interventions (Zinbarg, Uliaszek, \& Adler, 2008). If anything, this study serves as a reminder of the importance of personality in the workplace and the necessity of organizations to maintain a program of systematic testing of their employees in order to better understand their current circumstances and needs.

\subsection{Limitations}

One possible limitation to the use of personality disorders as a framework for understanding leader development is the issue of comorbidity. Prior research has indicated that personality disorders tend to co-occur so it is difficult to determine which characteristic is ultimately responsible for dysfunctional behaviors (Clark, 2007). This problem, however, is unlikely to impact the present results as we found little evidence of high intercorrelations between the subclinical traits assessed by the HDS. Further, the HDS manual shows little evidence that this limitation has carried over from the clinical assessments of personality disorders to the assessment of subclinical traits (Hogan \& Hogan, 1997).

Another potential limitation is that the participants may be abnormal compared with other populations. Not only does the present sample come from a military population, but it underwent a significant selection process which may have limited the personality variance typically seen in working populations. Moreover, prior research has indicated that subclinical traits such as narcissism undergo substantial developmental changes over time (Roberts, Edmonds, \& Grijalva, 2010). Consequently, the present sample may have elevated scores on most of the HDS dimensions. We did, in fact, find higher means in the present sample than have been reported in the published norming samples (Hogan \& Hogan, 1997), but it is unlikely that this would have inflated our results. Conversely, both the high selection ratio and the elevated trait levels would have served to limit the effect sizes found because of the reduced variance caused by range restriction. Consequently, our results may be conservative estimates of the relationship expected to be found between subclinical traits and leader development over time. Additionally, the leader 
development program that our sample was undergoing was intense and lengthy. While this sample facilitated assessing the effects of personality on leader development over time, most leaders do not have access to such a program. This setting does, however, showcase the possibilities associated with lengthy and intensive programs. This should encourage further research in such immersive and long-term development opportunities.

As this study was conducted with young leaders who may be particularly responsive to leader development programs, future research should also assess whether subclinical traits have similar effects in adult samples. As the unique context may have also influenced our effects, replication studies using adult samples should be conducted in both military and business contexts. Indeed military contexts are thought to create unique contingencies (Hannah, Woolfolk, et al., 2009). Further, while development persisted in this sample over the three years, this may be in part because the development program persisted over this entire timeframe. Future research should assess the extent to which leader development sustains after such a program ends.

Another potential limitation is that the changes in leader development were significant yet not substantial. This finding has also been found in similar studies concerned with the dynamic nature of leader performance over time (e.g. Mullen 2007). As in previous research, one likely cause of this lack of effect size is that the leaders in the present study had previously been competitively selected for USMA for their excellence on qualities highly relevant to leadership. As a result, their initial ratings of leadership were likely substantially higher than would be expected if random individuals were selected into the program. Consequently, for many individuals, there was less improvement possible in the ratings. That said, future research on the topic of the role of individual differences in leader development may wish to make use of samples where selection into leadership roles is not based heavily on factors associated with leader effectiveness or is even manipulated experimentally to ensure random assignment.

\subsection{Future directions}

Beyond the potential avenues for research mentioned above, if we take a dynamic approach to leader personality (Hannah, Woolfolk, et al. 2009), one potential direction for future research would be to consider the interaction between changes in leadership and changes in personality. Prior research has demonstrated that personality development often involves corresponsive effects (Caspi, Roberts, \& Shiner 2005; Harms, Roberts, \& Winter 2006). That is, that the individual differences that make one successful in a given setting are also the characteristics that change in response to that setting. While the current research demonstrates how personality can have an effect on leader development over time, it remains mostly unclear as to how attaining leadership positions and successfully (or unsuccessfully) operating in that role may, in turn, change personality over time. We are aware of only two studies that have explored this possibility. In a study of New Zealanders, Roberts, Caspi, and Moffitt (2003) found that attaining leadership positions was associated with increases in well-being, social potency, and achievement orientation over eight years. These were also the personality traits most associated with attaining leadership positions over time. Likewise, in an archival sample of Harvard students Harms (2010) found that the motives for Power and Achievement most associated with attaining leadership positions in student organizations increased in response to attaining those positions over four years. It would be particularly interesting for future research to evaluate the effects of work experiences or leadership training on changes in subclinical traits over time.

Another future direction would involve testing other domains of personality to evaluate which ones are most related to leader development over time. Because so little research on this topic has been done, it is not yet clear which domains would be most relevant. One necessary future research project would involve testing for the relative impact of both bright side and dark side traits as moderators of leader development over time. Based on prior theory and research, it is likely that such research would find positive effects for traits such as Openness to Experience that may increase self-awareness and self-insight or Conscientiousness, which may be linked with a motivation to improve oneself (Dominick et al. 2004). Once these effects are taken into account, the effects of certain subclinicals such as Dutiful and Diligent, which are currently potentially confounded with Conscientiousness could be better evaluated.

Along a similar vein, future research could explore other domains of personality beyond the Big Five. One domain that presents some potential is that of emotional intelligence. Although recent research (Harms \& Credé 2010) has shown the relationship between emotional intelligence and effective leadership styles is small to negligible, the proposed relationship between emotional intelligence and self-awareness (Sosik \& Megarian 1999) indicates that it is possible that emotional intelligence could be linked with responsiveness to leader development interventions. Further, theoretical work on developmental readiness (Avolio \& Hannah 2009; Hannah \& Avolio 2010) inclusive of the personality dimension of goal orientation, as well as other individual differences (self-awareness, developmental efficacy or confidence, self-complexity, and meta-cognitive ability) should be assessed along with other bright and dark personality indicators to test their separate and combined effects on development.

One other interesting potential avenue for future research would be to evaluate which leader development programs are most or least likely to have their success moderated by personality factors. Above and beyond this, it would be interesting to evaluate whether or not there were differences in which specific personality factors impacted different methods of leader development. For example, programs that focused on self-insight and reasoning may be more susceptible to subclinical traits and intelligence whereas programs that utilized a more hands-on, experiential approach may be more dependent on sociability and emotional intelligence. Further, a recent meta-analysis of 200 leadership intervention studies demonstrated that the effects of leadership interventions varied based on the type of leadership theory (e.g., transformational or Pygmalion leadership) that was the target for change (Avolio, Reichard, Hannah, Walumbwa, \& Chan 2009). This raises the question of whether personality may have more or less of a role in influencing development based on the specific theory or model of leadership being developed. 


\section{Conclusions}

This study set out to determine what role subclinical personality traits played in leader development over time. We discovered not only that personality traits were important for development, but that these effects persisted over multiple years. Moreover, we demonstrated that the nature of subclinical traits was far more complex than originally thought. While certain subclinical traits proved to be robust inhibitors of development, others showed positive or mixed effects with performance and development. Given the relative newness of this field, these results indicate that there is a great deal of research to be done before we can fully understand either subclinical traits or the role of personality in leader development in general.

\section{References}

American Psychiatric Association (1994). Diagnostic and statistical manual of mental disorders (4th ed.). Washington, DC: Author.

Atwater, L., Roush, P., \& Fischthal, A. (1995). The influence of upward feedback on self- and follower ratings of leadership. Personnel Psychology, 48, 35-59.

Atwater, L., Waldman, D., Atwater, D., \& Cartier, P. (2000). An upward feedback field experiment: Supervisors' cynicism, reactions, and commitment to subordinates. Personnel Psychology, 53, 275-297.

Avolio, B. (2005). Leadership development in the balance. Mahwah, NJ: Lawrence Erlbaum.

Avolio, B., \& Hannah, S. (2009). Leader developmental readiness. Industrial and Organizational Psychology, 2, $284-287$.

Avolio, B. J., Reichard, R. J., Hannah, S. T., Walumbwa, F. O., \& Chan, A. (2009). A meta-analytic review of leadership impact research: Experimental and quasiexperimental studies. The Leadership Quarterly, 20, 764-784.

Babiak, P., \& Hare, R. (2006). Snakes in suits: When psychopaths go to work. New York: HarperCollins Publishers, Inc.

Barrick, M., \& Mount, M. (1991). The Big Five personality dimensions and job performance: A meta-analyis. Personnel Psychology, 44, 1-26.

Benson, M., \& Campbell, J. (2007). To be, or not to be, linear: An expanded representation of personality and its relationship to leadership performance. International Journal of Selection and Assessment, 15, 232-249.

Bliese, P. D. (2002). Multilevel Modeling in R: A brief introduction to R, the multilevel package, and the NLME package. : Walter Reed Army Institute of Research.

Bliese, P. D., \& Ployhart, R. E. (2002). Growth modeling using random coefficient models: Model building, testing and illustrations. Organizational Research Methods, 5, 362-388.

Brett, J., \& Atwater, L. (2001). 360 feedback: Accuracy, reactions, and perceptions of usefulness. The Journal of Applied Psychology, 86, 930-942.

Brookmire, D. (2007). The time value of improved performance: Dealing with executives who have fatal flaws. Human Resource Planning, $30,5-7$.

Brunell, A., Gentry, W., Campbell, W. K., Hoffman, B., Kuhnert, K., \& DeMarree, K. (2008). Leader emergence: The case of the narcissistic leader. Personality and Social Psychology Bulletin, 34, 1663-1676.

Burke, M., \& Day, R. (1986). A cumulative study of the effectiveness of managerial training. The Journal of Applied Psychology, 71, $232-245$.

Cannon, M., \& Witherspoon, R. (2005). Actionable feedback: Unlocking the power of learning and performance improvement. Academy of Management Executive, $19,120-134$.

Caspi, A., Roberts, B. W., \& Shiner, R. (2005). Personality development: Stability and change. Annual Review of Psychology, 56, $453-484$.

Cavanagh, M. (2005). Mental health issues and challenging clients in executive coaching. In M. Cavanagh, A. Grant, \& T. Kemp (Eds.), Evidence-based coaching: Contributions from the behavioral sciences, Vol. 1. (pp. 21-36)Bowen Hills, Queensland: Australian Academic Press.

Chatman, J., \& Barsade, S. (1995). Personality, organization culture, and cooperation: Evidence from a business simulation. Administrative Science Quarterly, 40, 423-443.

Clark, L. A. (2007). Assessment and diagnosis of personality disorder: Perennial issues and an emerging reconceptualization. Annual Review of Psychology, 58, 227-257.

Collins, D., \& Holton, E. (2004). The effectiveness of managerial leadership development programs: A meta-analysis of studies from 1982 to 2001. Human Resource Development Quarterly, 15, 217-248.

Colquit, J., LePine, J., \& Noe, R. (2000). Toward an integrative theory of training motivation: A meta-analytic path analysis of 20 years of research. The Journal of Applied Psychology, 85, 678-707.

Davies, M. (2004). Prediction of transformational leadership by personality constructs for senior Australian organizational executive leaders. Unpublished dissertation, Griffith University.

Day, D. (2001). Leadership development: A review in context. The Leadership Quarterly, 11, 581-613.

Day, D., Harrison, M., \& Halpin, S. (2009). An integrative approach to leader development: Connecting adult development, identity, and expertise. New York: Routledge.

Dinglfield, S. (2004). Treatment for the 'untreatable'. Monitor on Psychology, 35, 46.

Dominick, P., Reilly, R., \& Byrne, J. (2004). Individual differences and peer-feedback: Personality's impact on behavior change. Paper presented at the Annual Conference of the Society for Industrial and Organizational Psychology, Chicago, IL.

Furnham, A., Crump, J., Batey, M., \& Chamorro-Premuzic, T. (2009). Personality and ability predictors of the "consequences" test of divergent thinking in a large non-student sample. Personality and Individual Differences, 46, 536-540.

Furnham, A., Crump, J., \& Chamorro-Premuzic, T. (2007). Managerial level, personality, and intelligence. Journal of Managerial Psychology, $22,805-818$.

Gable, M., \& Dangello, F. (1994). Job involvement, Machiavellianism, and job performance. Journal of Business and Psychology, 9, $159-170$.

Goldberg, L. (1993). The structure of phenotypic personality traits. The American Psychologist, 48, 26-34.

Hannah, S. T., \& Avolio, B. (2010). Ready or not: How do we accelerate the developmental readiness of leaders? Journal of Organizational Behavior, $31,1181-1187$.

Hannah, S. T., \& Lester, P. (2009). A multilevel approach to building and leading learning organizations. The Leadership Quarterly, $20,34-48$.

Hannah, S. T., Uhl-Bien, M., Avolio, B. J., \& Cavarretta, F. (2009). A framework for leadership in extreme contexts. The Leadership Quarterly, $20,897-919$.

Hannah, S. T., Woolfolk, L., \& Lord, R. G. (2009). Leader self-structure: A framework for positive leadership. Journal of Organizational Behavior, 30, 269-290.

Harkness, A., \& Lilienfield, S. (1997). Individual differences science for treatment planning: Personality traits. Psychological Assessment, 9, 349-360.

Harms, P.D. (2010). Status attainment and personality change over time. Unpublished manuscript.

Harms, P. D., \& Credé, M. (2010). Emotional intelligence and transformational and transactional leadership: A meta-analysis. Journal of Leadership and Organizational Studies, 17, 5-17.

Harms, P. D., Roberts, B. W., \& Winter, D. (2006). Becoming the Harvard man: Person-environment fit, personality development, and academic success. Personality and Social Psychology Bulletin, 32, 851-865.

Hoffman, B., Woehr, D., Maldagen-Youngjohn, R., \& Lyons, B. (2011). Great man or great myth? A quantitative review of the relationship between individual differences and leader effectiveness. Journal of Occupational and Organizational Psychology, 84, 347-381.

Hogan, R. (2007). Personality and the fate of organizations. Mahwah, NJ: Lawrence Erlbaum Assoc.

Hogan, R., \& Hogan, J. (1997). Hogan Development Survey Manual. Tulsa, OK: Hogan Assessment Systems.

Hogan, R., \& Hogan, J. (2001). Assessing leadership: A view from the dark side. International Journal of Selection and Assessment, 9, 40-51.

Hogan, R., Hogan, J., \& Kaiser, R. (2010). Management derailment: Personality assessment and mitigation. In S. Zedeck (Ed.), American Psychological Association Handbook of Industrial and Organizational Psychology. Washington, D.C.: American Psychological Association.

Hogan, R., \& Kaiser, R. (2005). What we know about leadership. Review of General Psychology, 9, 169-180.

Hogan, R., \& Warrenfeltz, R. (2003). Educating the modern manager. Academy of Management Learning and Education, 2, 74-84.

John, O., Robins, R., \& Pervin, L. (2008). Handbook of personality: Theory and research. New York: The Guilford Press. 
Judge, T., Bono, J., Ilies, R., \& Gerhardt, M. (2002). Personality and leadership: A qualitative and quantitative review. The Journal of Applied Psychology, 87, $765-780$.

Judge, T., Piccolo, R., \& Kosalka, T. (2009). The bright and dark sides of leader traits: A review and theoretical extension of the leader trait paradigm. The Leadership Quarterly, 20, 855-875.

Kail, E. (2007). Does personality predict perceived performance change following a leader development intervention? Unpublished dissertation. North Carolina State University.

Kaiser, R. \& Craig, B. (2004). What gets you there won't keep you there: Managerial behaviors related to effectiveness at the bottom, middle, and top. Paper presented at the Annual Conference of the Society for Industrial and Organizational Psychology, Chicago, IL.

Khoo, H., \& Burch, G. (2008). The 'dark side' of leadership personality and transformational leadership: An exploratory study. Personality and Individual Differences, 44, 86-97.

Kippenberger, T. (1997). The dark side of leadership: What drives people to become leaders? The Antidote, 2, 11-13.

Kluger, A., \& DeNisi, A. (1996). The effects of feedback interventions on performance: A historical review, a meta-analysis, and a preliminary feedback intervention theory. Psychological Bulletin, 119, 254-284.

Leichsenring, F., \& Leibing, E. (2003). The effectiveness of psychodynamic therapy and cognitive behavior therapy in the treatment of personality disorders: A meta-analysis. The American Journal of Psychiatry, 160, 1223-1232.

Leslie, J., \& Van Velsor, E. (1996). A look at derailment today: North America and Europe. Greensboro, NC: Center for Creative Leadership.

Lievens, F., Ones, D., \& Dilchert, S. (2009). Personality scale validities increase throughout medical school. The Journal of Applied Psychology, 94, 1514-1535.

Lindberg, J. (2006). The relative and incremental validity of the Big Five and maladaptive personality characteristics for predicting leadership effectiveness. Unpublished thesis, North Carolina State University.

Lindsay, D., Foster, C., Jackson, R., \& Hassan, A. (2009). Leadership education and assessment: A developmental approach. Journal of Leadership Education, 8 , 163-176.

Linley, P. A., Woolston, L. \& Biswas-Diener, R. (2009). Strengths coaching with leaders. International Coaching Psychology Review, 4, 37-48.

Lombardo, M., Ruderman, M., \& McCauley, C. (1988). Explanations of success and derailment in upper-level management positions. Journal of Business and Psychology, 2, 199-216.

Maccoby, M. (2003). The productive narcissist: The promise and peril of visionary leadership. New York: Broadway Books.

McCauley, C. (2008). Leader development: A review of research. Unpublished manuscript.

McCormick, I., \& Burch, G. (2008). Personality-focused coaching for leadership development. Consulting Psychology Journal: Research and Practice, 60, 267-278.

McCrae, R., \& Costa, P. (1995). Trait explanations in personality psychology. European Journal of Personality, 9, 231-252.

Miller, J., Lynam, D., Widiger, T., \& Leukefeld, C. (2001). Personality disorders as extreme variants of common personality dimensions: Can the Five-Factor Model adequately represent psychopathy? Journal of Personality, 69, 253-276.

Moscoso, S., \& Salgado, J. (2004). "Dark side" personality styles as predictors of task, contextual, and job performance. International Journal of Selection and Assessment, 12, 356-362.

Mulder, R. (2002). Personality pathology and treatment outcome in major depression: A review. The American Journal of Psychiatry, 159, 359-371.

Mullen, T. (2007). How long should we follow the leader? Using latent growth models of longitudinal leadership performance to predict leader outcomes. Unpublished dissertation, North Carolina State University.

Nelson, E., \& Hogan, R. (2009). Coaching on the dark side. International Coaching Psychology Review, 4, 9-24.

Padilla, A., Hogan, R., \& Kaiser, R. (2007). The toxic triangle: Destructive leaders, susceptible followers, and conducive environments. The Leadership Quarterly, 18, 176-194.

Paulhus, D. (1998). Interpersonal and intrapsychic adaptiveness of trait self-enhancement. Journal of Personality and Social Psychology, 74, $197-208$.

Paulhus, D. L., \& Williams, K. (2002). The dark triad of personality: Narcissism, Machiavellianism, and Psychopathy. Journal of Research in Personality, $36,556-568$.

Penney, L., \& Spector, P. (2002). Narcissism and counterproductive work behavior: Do bigger egos mean bigger problems? International Journal of Selection and Assessment, 10, 126-134.

Popper, M., \& Mayseless, O. (2007). The building blocks of leader development: A psychological conceptual framework. Leadership and Organizational Development Journal, 28, 664-684.

Rath, T., \& Conchie, B. (2009). Strengths-based leadership. New York: Gallup Press.

Roberts, B. W., Caspi, A., \& Moffitt, T. (2003). Work experiences and personality development in young adulthood. Journal of Personality and Social Psychology, 84, 582-593.

Roberts, L. M., Dutton, J. E., Spreitzer, G. M., Heaphy, E. D., \& Quinn, R. E. (2005). Composing the reflected best-self portrait: Building pathways for becoming extraordinary in work organizations. Academy of Management Review, 30, 712-736.

Roberts, B. W., Edmonds, G., \& Grijalva, E. (2010). It is developmental me, not generation me: Developmental changes are more important than generational changes in narcissism-Commentary on Trzesniewski \& Donnellan. Perspectives on Psychological Science, 5, 97-102.

Roberts, B. W., Harms, P. D., Smith, J., Wood, D., \& Webb, M. (2006). Methods in personality psychology. In M. Eid, \& E. Diener (Eds.), Handbook of Psychological Assessment: A Multimethod Perspective (pp. 321-335). Washington, D.C.: American Psychological Association.

Roberts, B. W., Wood, D., \& Caspi, A. (2008). The development of personality traits in adulthood. In O. John, R. Robins, \& L. Pervin (Eds.), Handbook of personality: Theory and research (pp. 375-398). New York: The Guilford Press.

Robins, R., Noftle, E., Trzesniewski, K., \& Roberts, B. W. (2005). Do people know how their personality has changed? Correlates of perceived and actual personality change in young adulthood. Journal of Personality, 73, 489-521.

Robins, R. W., \& Paulhus, D. L. (2001). The character of self-enhancers: Implications for organizations. In B. W. Roberts, \& R. Hogan (Eds.), Personality psychology in the workplace (pp. 193-222). Washington, D.C.: American Psychological Association.

Schnure, K. (2010). Narcissism levels and ratings of executive leadership potential. Paper presented at the Annual Conference of the Society for Industrial and Organizational Psychology, Atlanta, GA.

Seifert, C. Yukl, G. \& McDonald, R. (2003). Effects of multisource feedback and a feedback facilitator on the influence behavior of managers towards subordinates. The Journal of Applied Psychology, 88, 561-569.

Singer, J. D. (1998). Using SAS PROC MIXED to fit multilevel, hierarchical, and individual growth models. Journal of Educational and Behavioral Statistics, 23, 323-355.

Singer, J. D., \& Willett, J. B. (2003). Applied longitudinal data analysis: Modeling change and event occurrence. New York: Oxford University Press.

Sosik, J. J., \& Megarian, L. E. (1999). Understanding leader emotional intelligence and performance: The role of self-other agreement on transformational leadership perceptions. Group Organization Management, 24, 367-390.

Stewart, L., Palmer, S., Wilkin, H., \& Kerrin, M. (2008). The influence of character: Does personality impact coaching success? International Journal of Evidence Based Coaching and Mentoring, 6, 32-42.

Tannenbaum, S., \& Yukl, G. (1992). Training and development in work organizations. Annual Review of Psychology, 43, 399-441.

Thoresen, C., Bradley, J., Bliese, P., \& Thoresen, J. (2004). The Big Five personality traits and individual job growth trajectories in maintenance and transitional job stages. The Journal of Applied Psychology, 89, 835-853.

Torregiante, J. (2005). Destructive personality traits and leadership performance: A pattern-oriented approach. Unpublished thesis, North Carolina State University. United States Military Academy (2009). Building capacity to lead: The West Point system for leaders development. NY: West Point.

Zinbarg, R., Uliaszek, A., \& Adler, J. (2008). The role of personality traits in psychotherapy for anxiety and depression. Journal of Personality, 76, $1649-1687$. 